\title{
Numerical study on thermal performance of tunnel lining with electrical heating system in cold region
}

\author{
Runlin Yang ${ }^{1, a}$ and Chengjin Ma1,b \\ ${ }^{1}$ Department of Civil Engineering, School of Civil and Resource Engineering, University of Science \\ and Technology Beijing, Beijing 100083, China \\ arlyang@ustb.edu.cn, bmcjin13@163.com
}

\begin{abstract}
Keywords: tunnel; lining; thermal insulation; temperature field; frost resistance.
Abstract. Application practice of tunnel engineering in cold area shows that the repeated seasonally freezing and thawing cycle of surrounding rock and soil can lead to further breakage and cracking of tunnel lining, resulting in the seepage and freezing of the pore water in surrounding rock and soil. The seeped water or the formed ice is attached to the lining or road surface, thus the potential dangers greatly threatens the traffic safety of the vehicle. It may seriously affect the normal use of the tunnel. Therefore, frost and seepage prevention of tunnel lining is an important problem in the cold region tunnel engineering. In view of this, in the project of the Jinzhangzi tunnel in Chengde, this paper analysis on the insulation effect of the tunnel lining in winter based on the electrical belts .In this paper, two kinds of tunnel lining are considered, one cases corresponding to the tunnel without any thermal insulation measure, and the other adopting the active heating system. The results of numerical simulation show that the installation of the electric heating system on the lining surface can ensure that the lining structure is under the ideal temperature field condition, which can effectively restrain the freezing and thawing damage.
\end{abstract}

\section{Introduction}

Because of the construction factor or the bearing load reason, the concrete structure interior especially near the surface is easy to produce the shrinkage crack and the load crack, usually does not affect the continued use. However, the situation is different for tunnel linings in cold areas. Once the inner surface of the lining cracks, the pore water in the surrounding rock and soil will gradually invade the lining, and freeze in the winter, causing the cracks to expand further. When it is severe, the water seeping into the lining forms a slender icicle that hangs inside the tunnel or forms a thick ice layer on the ground. In the spring, the tunnel lining may have a wide range drip phenomenon due to warmer temperatures of the ice melting. In the North, northeast and northwest of China, such problems must be taken into account.

The insulation way of tunnel lining is divided into active heating and passive insulation. Active heating system need the tunnel power supply, and it will consume a lot of energy. Passive insulation does not require external energy, mainly by paving the lining surface through the insulation material, isolate the external cold air, thus avoiding environmental temperature impact. Because the active heating effect is obvious, therefore it may be considered in the cold.

Aiming for Jinzhangzi tunnel lining structure, this paper intends to consider the use of constant power electrical belts for active heating, and then the numerical simulation of thermal insulation effect is carried out by using ANSYS software. By comparing with the active heating system or not under the different conditions of the tunnel lining and the surrounding rock temperature field, to confirm the effectiveness of the actual measures of active insulation measures. 


\section{Engineering background}

The Jinzhangzi tunnel belongs to the National Highway 101 line in Pingquan county, Chengde city. The main surrounding rock is so-called Anshan Rock. The fracture of the rock is obvious, and the fissure water is rich. The length of the tunnel is $480 \mathrm{~m}$. The primary lining adopts the $\mathrm{C} 25$ reinforced concrete, and its thickness is $8 \mathrm{~cm}$. The secondary lining is the $\mathrm{C} 25$ reinforced concrete, and its thickness is $30 \mathrm{~cm}$. The tunnel model dimension is shown in Figure 1.

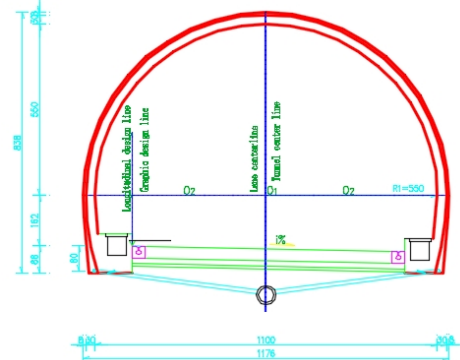

Fig. 1 Dimension of the target tunnel

\section{Working principle of thermal protective system}

The active heating system assumes the electrical heating belt system which are laid on the concrete lining surface. The electrical group system is a radiant heating system, which converts electrical energy into heat energy through a heating cable and then transmits it to the lining structure to achieve the desired thermal performance effect. The setup of the typical electric heating system is shown in Fig. 2, including the heating cable, the temperature controller, the thermal sensor, the foil reflective layer and the auxiliary spraying layer. The heating cable is used for converting electrical energy into heat energy, and the temperature sensor for measuring temperature of the lining surface. The temperature controller can control the working temperature of electrical belts. The aluminum foil reflective layer aim to provide the radiant heat energy as much as possible to the concrete lining, and the auxiliary spraying layer can prevent the heat energy from escaping into the ambient air.

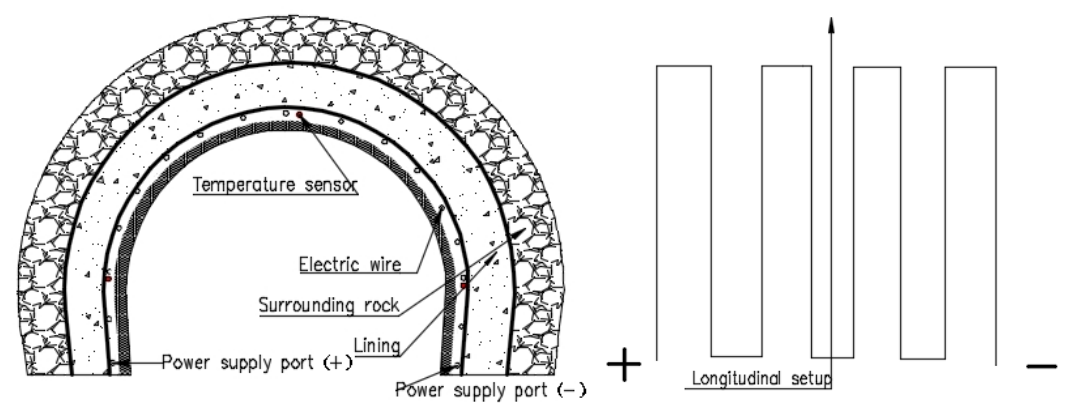

Fig. 2 Schematic diagram of the active heating system

In the process of numerical simulation, it is assumed that the constant-power heating belt is used. The line power of the electrical belts is $10 \mathrm{~W} / \mathrm{m}$ and its laying spacing is $10 \mathrm{~cm}$.

\section{Computational model and main parameters}

Computational model. It is well known that the temperature inside of the tunnel is affected by the atmospheric temperature. The environment can exert an impact influence upon temperature of the concrete lining, especially, the temperature of the entrance or the exit of the tunnel is lowest, and therefore a $10 \mathrm{~m}$ long part from the entrance of the tunnel is taken as the computational model. Its dimensions are simplified as follows: the width is $11 \mathrm{~m}$, the height is $8 \mathrm{~m}$, and the thickness of the lining is $38 \mathrm{~cm}$. Obviously, the initial temperature which apply to lining surface of the tunnel is the 
same as environmental temperature, and correspond thermal simulation are carried out. The finite element calculation models are shown in Figure 3 and Figure 4 respectively:

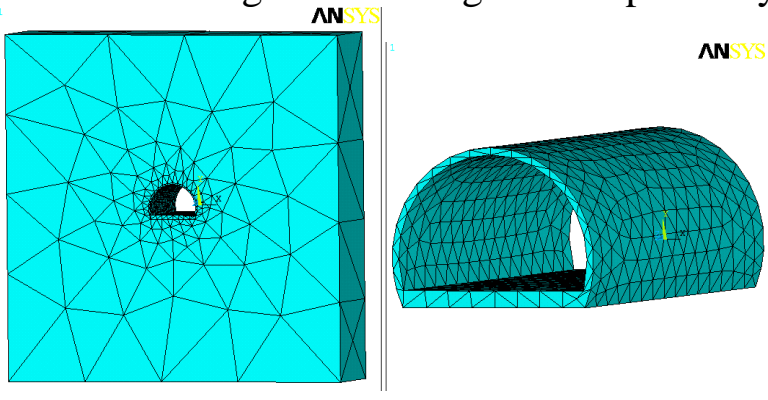

Fig. 3 Computational model without protective measure

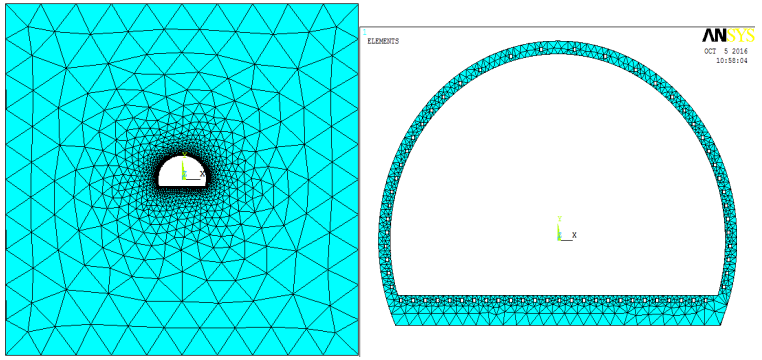

Fig. 4 Computational model with electrical heating belts

Main parameters. Thermal performance of the tunnel structure involves the thermodynamic properties of the lining and the surrounding rock, which need to be considered from two angles. From the angle of material, it is mainly related to the thermal physical parameters of the lining and the surrounding rock material, including thermal conductivity, specific heat and density, and from the angle of structure, it is influenced by the porosity and water content of the structure. For the sake of simplicity, it is assumed that the tunnel structure is composed of each layer is isotropic, and the material calculation model is considered by linear elasticity, and the thermal physical parameters of the concrete lining and the surrounding rock are given in table 1 respectively.

Table 1 Thermal Physical parameters

\begin{tabular}{lccc}
\hline Materials & $\begin{array}{l}\text { Coefficient of thermal } \\
\text { conductivity } /\left(\mathrm{W} /\left(\mathrm{m} \cdot{ }^{\circ} \mathrm{C}\right)\right)\end{array}$ & $\begin{array}{l}\text { Specific heat } \\
/\left(\mathrm{kJ} /\left(\mathrm{kg} \cdot{ }^{\circ} \mathrm{C}\right)\right)\end{array}$ & Density $/\left(\mathrm{kg} \cdot \mathrm{m}^{-3}\right)$ \\
\hline Concrete & 1.74 & 0.92 & 2500 \\
\hline Surrounding rock & 3.49 & 0.92 & 2800 \\
\hline
\end{tabular}

Boundary conditions of the model. The heating belt works under constant-power, and the thermal flux can be converted according to the line power (1).

$$
q_{s}=\frac{q_{1}}{3.14 d}
$$

Formula: $q_{s}$----- Thermal flux on cable surface $\mathrm{W} / \mathrm{m}^{2}$;

$$
\begin{aligned}
& q_{1} \text {---- Line power rating } \mathrm{W} / \mathrm{m} \text {; } \\
& \mathrm{d} \text {---- Diameter of the cable } \mathrm{m} \text {. }
\end{aligned}
$$

According to the local statistic data, the concrete lining surface chooses the minus 20 degree centigrade as the initial temperature. The convective heat transfer coefficient is $15 \mathrm{w} / \mathrm{m}^{2} \cdot{ }^{\circ} \mathrm{C}$ between the cold air and the surface of tunnel lining. The temperature of deepest is considered constant and the corresponding value is select as $3{ }^{\circ} \mathrm{C}$. 


\section{Numerical simulation}

In the first step, the initial temperature field need be determined, and the steady state thermal can be used to determine the steady temperature field of tunnel lining and surrounding rock at low temperature. Consequently, the initial temperature field of lining and surrounding rock is derived,its given in Fig.5.

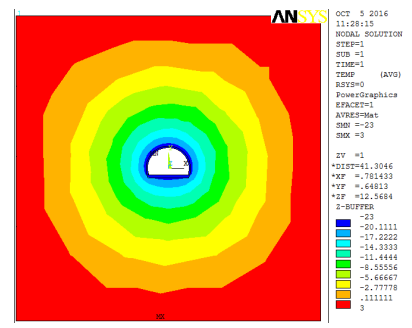

Fig. 5 Initial temperature field distribution of the tunnel lining and surrounding rock

According to the boundary condition and the line power of electrical belts, the thermal analysis of the finite element model can be used for analyzing the thermal performance and heating system.As shown in Fig.6.

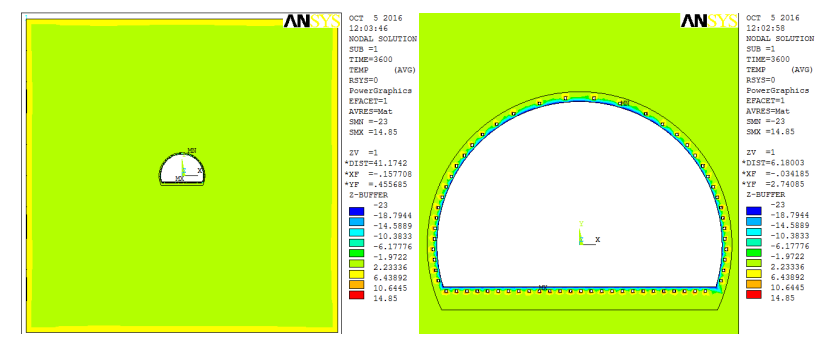

Fig.6 Temperature field distribution of the tunnel lining and surrounding rock

In order to evaluate the thermal effect of active heating system, the temperature curve is given in Fig.7.It can be seen that the proposed heating system is effective for frost damage prevention of the tunnel.

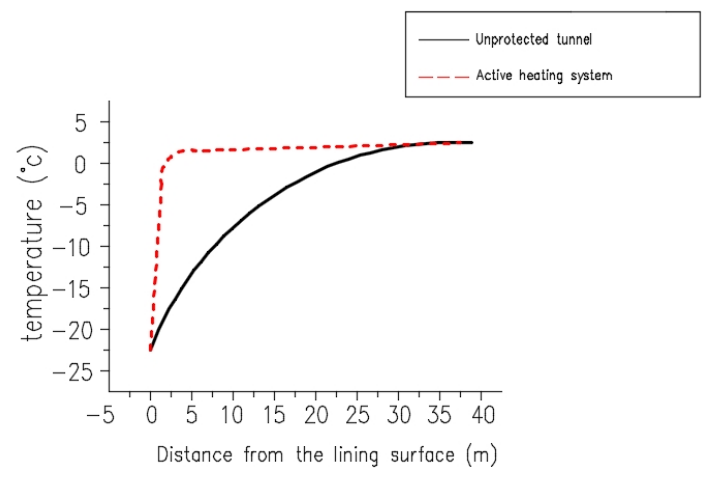

Fig. 7 Comparison of thermal performance at different position

(1) For the tunnel without any protective measure, the lining surface temperature and atmospheric temperature is basically close. A deep range of the concrete along the radial direction of the tunnel may occur frost damage problem;

(2) The farther away from the outer surface of the concrete lining of the tunnel lining and the surrounding rock mass, the higher the temperature is.IE the less the temperature is affected by the outside environment.

(3) When adopting the active heating system, the inner temperature of lining and surrounding rock is higher, which is affected by ambient temperature only in a thin layer of concrete near the outer surface of lining, and the effect of heat thermal insulation. 


\section{Conclusions}

Through numerical simulation, it can be found that in the cold region tunnel, the active heating system can effectively solve $t$ the frost-resistive problem of the tunnel, it may be considered a new approach to protect the tunnel lining in cold weather.

\section{References}

[1] Huijun Jin,Shuxun Li, Shaoling Wang, Lin Zhao. Effects of climate change on the environment of permafrost and cold regions in China [J]. Geography Journal, 2000, 02:161-173.

[2] Guanglong Zhang. Study on heat preservation and frost-proof test and numerical simulation of tunnel in cold zone based on electric heating [D]. Chang'an University, 2012

[3] Yuanming Lai,Wenbing Yu, Ziwang Wu, He Ping, Mengxi Zhang . Analytic solution of temperature field of circular cross section tunnel in cold region [J]. Glacial permafrost, 2001, 02:126-130.

[4] Yanling Luo,Ping Cao. Development and application of self-control temperature heating cable [J]. Chemical production and Technology, 2000, 01:20-22+3.

[5] Caihua Sun. Numerical analysis of heat transfer by finite element method [J]. Journal of Qinghai Normal University (natural Science Edition), 2013, 01:31-33+44.

[6] Gang Deng. Design of tunnel anti-frost damage in high altitude cold zone [D]. Southwest Jiaotong University, 2012

[7] Haiqin Wu. Study on the technology of heating cable for melting snow ice in pavement [D]. Beijing University of Technology, 2005 